\title{
Editorial: ASAP Three Years On
}

\author{
John Stillwell • Mark Birkin
}

Received: 1 February 2011 / Accepted: 2 February 2011 /

Published online: 12 February 2011

(C) Springer Science+Business Media B.V. 2011

Three years have elapsed since we launched Applied Spatial Analysis and Policy, during which time nine issues of the journal have been produced in three volumes and the publication has begun to receive recognition around the world as an outlet for reporting high quality applied spatial research. Moreover, there has been increased attention given in many parts of the world to ensuring that research in social science delivers maximum impact upon those operating in user or practitioner communities as policy makers. Nowhere is this more clearly observed than in the United Kingdom, where research and funding councils have prioritized their efforts to identify and reward the impact that excellent research has had on society and the economy, and to encourage academic researchers to achieve the full potential impact of their research activity in the future.

There has been a steady flow rather than a flood of papers submitted to ASAP since we first announced the journal's existence and advertised for contributions during 2007, but it has been encouraging that the journal has received manuscripts from a wide range of countries across the world. Whilst the majority of papers tend to originate in the United Kingdom or the United States, submissions have also been made from authors in Australia, Bangladesh, Botswana, Brazil, Canada, China, Denmark, France, Germany, India, Iran, Israel, Italy, Japan, Malaysia, Mexico, The Netherlands, New Zealand, Nigeria, Sweden, Switzerland, Thailand, Trinidad and Tobago and the United Arab Emirates. The vast majority of the papers submitted to ASAP have been jointly authored.

As editors, we owe a huge debt of gratitude to those individuals who have assisted in the refereeing process, providing authors with valuable feedback which frequently results in the transformation of original manuscripts into really excellent papers. Pressures on those in higher education seem to mount inexorably and consequently the job of refereeing tends to be pushed lower and lower down the list of priorities, yet without the contributions that referees make, the whole peer review system

J. Stillwell $(\bowtie) \cdot$ M. Birkin

University of Leeds, Leeds, UK

e-mail: J.C.H.Stillwell@leeds.ac.uk 
would collapse. Thus, with the much valued assistance of our referees, we have been able to accept $60 \%$ of those papers that have completed the submission and refereeing process, many of which have undergone substantial revision; the rejection rate for ASAP is around $30 \%$ and around $10 \%$ of papers submitted have been subsequently withdrawn.

The article download statistics presented on the Springer web site for ASAP ${ }^{1}$ report the number of downloads over the last seven, thirty and ninety days respectively and indicate that approximately 30 downloads of ASAP papers are undertaken per day. The first prize for the most frequently downloaded article goes to Paul Torrens for his paper on 'A toolkit for measuring sprawl', the first article to be published in the first issue of ASAP. Torrens' paper was downloaded 167 times in the ninety days before 2 February 2011. Other popular downloads in this same ninety day period were as follows:

- Eric Koomen, Arjen Koekoek and Egbert Dijk on 'Simulating land use change in a regional planning context' (126 downloads);

- Jeroen Neuvel, Henk Scholten and Adri ven den Brink on 'From spatial data to synchronized actions: the network-centric organization of spatial decision support for risk and emergency management' (94 downloads);

- Stephen Clark and Andrew Finley on 'Spatial modelling of car ownership data: a case study from the United Kingdom' (93 downloads); and

- Frank Southworth on 'Multi-criteria sensor placement for emergency response' (91 downloads).

Each of the first three volumes of ASAP has contained approximately 250 pages with around 12 papers and a number of book reviews in each. Issues 2 and 3 of Volume 3 were amalgamated to provide sufficient space for ASAP's first Special Issue on 'Poverty and Deprivation Mapping' which was guest edited by Paul Norman from the University of Leeds. Moreover, at the beginning of 2011, 15 articles and five book reviews had been published Online First ${ }^{\mathrm{TM}}$, a facility which has considerable appeal for those wishing to see relatively quick publication of their work. Further special issues are planned for the future.

The quantity of papers available Online First ${ }^{\mathrm{TM}}$ and our prospects for expanding the number of submissions to ASAP over the next three years are the two main reasons behind the decision to increase the number of ASAP volumes to four per year. This volume, therefore, represents the first of the new series and we hope that readers will find its content to be interesting and valuable. As we said three years ago, our goal for ASAP remains the same: to develop a reputation for publishing articles that the research and user communities consider to have research quality, lasting impact and scientific excellence. If we are to succeed, it is essential that we continue to receive your manuscripts—-so please keep them coming!

\footnotetext{
$\overline{{ }^{1} \text { See ASAP web site at http://www.springer.com/social+sciences/population+studies/journal/12061 }}$
} 